\title{
Strategies to enhance graft performance in cord blood transplantation
}

\author{
Keon Hee Yoo ${ }^{1,2,3}$ \\ ${ }^{1}$ Department of Pediatrics, Samsung Medical Center, Sungkyunkwan University School of Medicine, Seoul, Korea \\ ${ }^{2}$ Stem Cell \& Regenerative Medicine Institute, Samsung Medical Center, Seoul, Korea \\ ${ }^{3}$ Department of Health Sciences and Technology, Samsung Advanced Institute for Health Sciences \& Technology, Sungkyunkwan \\ University, Seoul, Korea
}

Received: October 14, 2020

Revised: November 1, 2020

Accepted: November 3, 2020

Corresponding author:

Keon Hee Yoo

Department of Pediatrics,

Samsung Medical Center,

Sungkyunkwan University

School of Medicine, 81 Irwon-ro,

Gangnam-gu, Seoul 06351, Korea

Tel: +82-2-3410-3532

E-mail: hema2170@skku.edu

\begin{abstract}
Umbilical cord blood (CB) serves as one of the alternative donor sources for hematopoietic stem cell transplantation (HSCT) in those patients lacking a matched related donor. However, the relatively high incidence of engraftment failure and/or delayed engraftment following cord blood transplantation (CBT) has been a major obstacle against its success. The usage of two $C B$ units has made $C B T$ possible in adults when a single $C B$ unit with an adequate cell number is lacking, but it failed to demonstrate any beneficial effect in children and adolescents. In recent years, unmanipulated haploidentical graft has been replacing CB owing to its rapid availability along with low incidence of acute and chronic graft-versus-host disease due to the usage of post-transplant cyclophosphamide. Given this situation, overcoming the engraftment related issues is crucial in order for CBT to remain a realistic alternative of allogeneic HSCT. This review discusses the engraftment-related issues in CBT and recent advances to overcome those, highlighting the role of conditioning, ex vivo CB stem cell expansion, and cotransplantation of mesenchymal stem/stromal cells.
\end{abstract}

Keywords: Conditioning; Cord blood transplantation; Engraftment; Ex vivo expansion; Mesenchymal stem cells
This is an Open Access article distributed under the terms of the Creative Commons Attribution Non-Commercial License (https:// creativecommons.org/licenses/ by-nc/4.0/).

\section{INTRODUCTION}

The first successful cord blood transplantation (CBT) dates back to 1988 when a boy with Fanconi anemia received cord blood (CB) from his human leukocyte antigen (HLA)-identical sibling [1]. This success proved the notion that hematopoietic stem cells (HSCs) residing in human CB is enough to repopulate human bone marrow following an immunoablative or myeloablative conditioning. This pioneering achievement was followed by the first successful CBT using unrelated CB, delivered from the New York Blood Center, in an adult with chronic myelogenous leukemia in 1996 [2]. Since then, over 700,000 CB units have been donated for public use, and tens of thousands of banked $C B$ have been used for alternative donor hematopoietic stem cell 
transplantation (HSCT) in patients with various malignant and non-malignant disorders lacking a matched related or matched unrelated donor [3]. However, the limited cell dose in a CB unit has often led to delayed engraftment or failed primary engraftment resulting in high incidence of infectious complications and unacceptably high non-relapse mortality [4-8]. Nonetheless, due to the rapid availability and less stringent HLA matching requirements, CB has become a useful alternative HSC source for patients who need urgent allogeneic HSCT $[9,10]$. Typically, the rate of neutrophil engraftment after CBT is in the range of $70 \%$ to $90 \%$ with a significant delay compared to that after other types of HSCT [4,11]. In a previous report by Yoo et al. [12], the rates of neutrophil and platelet recovery were approximately $90 \%$ and $75 \%$, respectively, with the overall survival rate of only $47.5 \%$ following CBT in Korean children and adolescents. Given that the delayed engraftment or primary engraftment failure has been the biggest hurdle to a successful CBT, strategies aiming at enhancing the graft performance are urgently needed in order for CBT to remain a realistic alternative of allogeneic HSCT.

Herein the engraftment-related issues in CBT and recent advances in promoting engraftment after CBT have been discussed. Undoubtedly, selecting the best available CB unit that is well matched and has an adequate number of cells is the most important strategy for a successful CBT. In addition, avoiding $\mathrm{CB}$ units where preformed host donor specific anti-HLA antibodies exist is also a common practice to prevent graft failure or delayed engraftment [13-15]. With these strategies having been repeatedly stressed numerously, other strategies aiming at enhancing engraftment will be highlighted, which include modifying conditioning regimens, ex vivo CB stem cell expansion, and cotransplantation of third party mesenchymal stem/stromal cells (MSCs). This review mainly focuses on pediatric recipients who are more likely to benefit from CBT, in the hope of implicating some of them in adults as well.

\section{HAPLOIDENTICAL TRANSPLANTATION VERSUS CBT}

According to the European Group for Blood and Marrow Transplantation (EBMT) activity survey report in 2017, the number of unrelated CBT has been decreasing while that of haploidentical transplantation has been rapidly increasing in recent years [16]. The situation is similar in Korea. In 2018, CBT accounted for only $3.9 \%$ of all alternative donor transplants in contrast to $34 \%$ in 2004 (data provided by the Korean Blood and Mar- row Transplantation Nurses Society). On the contrary, haploidentical transplantation was seldom performed until the mid-2000s, but it accounted for $45.9 \%$ of all alternative donor transplants in 2018 in Korea (data provided by the Korean Blood and Marrow Transplantation Nurses Society). These trends are largely attributed to recent advances in haploidentical transplantation using post-transplant cyclophosphamide, which has proved effective in preventing severe graftversus-host disease (GVHD) without the need for ex vivo T-cell depletion [17-19]. In addition, a haploidentical donor is usually rapidly available, and an adequate cell number is guaranteed in most cases. According to a recent retrospective study by the Eurocord-EBMT, the rates of overall survival, leukemia-free survival, and GVHD-free/relapse-free survival (GRFS) were significantly lower after CBT than those after haploidentical transplantation in adult patients with leukemia [20]. A more recent prospective randomized study by Sanz et al. [21] also revealed lower rates of disease-free survival and GRFS in adult $\mathrm{CB}$ recipients. These findings explain the general preference of physicians for a haploidentical transplantation over a CBT in adults when a matched related or matched unrelated donor is lacking. However, the situation is somewhat different in children. According to recent studies including a meta-analysis, the outcome measures for the two transplant modalities for childhood leukemia were comparable $[22,23]$. Given that CBT has advantages such as a low rate of chronic GVHD and a greater graft-versus-leukemia/graft-versus-malignancy (GVL/GVM) effect compared to other transplant modalities [24,25], establishing effective strategies to overcome its current limitations is expected to revitalize the use of $C B$ especially for pediatric patients.

\section{CB ENGRAFTMENT AND SURVIVAL IN PEDIATRIC MALIGNANCY}

In a recent Japanese nationwide retrospective study comparing the donor sources in childhood acute leukemia, both neutrophil and platelet recovery after unrelated CBT were significantly delayed compared to those after unrelated bone marrow transplantation (BMT) [26]. The cumulative incidences of neutrophil recovery after matched related BMT, unrelated BMT, and unrelated CBT were 100\%, 96.8\%, and $86.6 \%$, respectively. The median time to neutrophil engraftment was 17 days for matched related BMT, 19 days for unrelated BMT, and 23 days for unrelated CBT. The cumulative incidences of platelet recovery by day 100 after HSCT were 98.1\% for matched related BMT, $91.2 \%$ for unrelated BMT, 
and $83.4 \%$ for unrelated CBT. Nevertheless, the incidences of acute GVHD after unrelated BMT and CBT were quite similar, and the incidence of chronic GVHD after CBT was lower compared to that after unrelated BMT. More importantly, the overall and leukemia-free survival rates after HLA identical sibling BMT (74.8\% and 69.6\%), unrelated BMT (69.0\% and $71.8 \%)$, and unrelated CBT (75.0\% and $63.8 \%$ ) were comparable. More recently, a multicenter retrospective analysis comparing the donor sources in childhood acute myeloid leukemia in Europe, Australia, and the United States also showed comparable relapse and survival rates in the recipients of matched sibling donor, matched unrelated donor, and single CB [27]. In this study, only double CBT had worse survival compared to matched sibling donor transplant (hazard ratio, $0.43 ; 95 \%$ confidence interval, 0.23 to $0.83 ; \mathrm{P}=$ 0.013), indicating a tendency toward a lower leukemia-free survival (hazard ratio, 0.56 ; $95 \%$ confidence interval, 0.3 to 1 ; $\mathrm{P}=0.058$ ) and a higher non-relapse mortality (hazard ratio, $0.42 ; 95 \%$ confidence interval, 0.16 to $1.1 ; P=0.071$ ). Notably, the median time to neutrophil engraftment was 17 days for matched sibling transplantation, 19 days for both matched unrelated transplantation $(P=0.31)$ and single $C B T(P=0.03)$, and 22 days for double CBT $(P<0.001)$. By 60 days, the rates of neutrophil engraftment were similar for all cell sources (approximately 95\%). However, CBT, whether single or double, showed an evident delay in platelet engraftment, and a substantial proportion of patients failed to achieve it. The inferiority of double CBT in that study is not very surprising since an earlier study already revealed no beneficial effect of double CBT in children and adolescents [28].

As noted in these studies, both neutrophil and platelet engraftment are delayed after CBT for childhood malignancy; the primary graft failure rate appears to be decreasing, while a substantial proportion of patients still fail to achieve platelet engraftment. Nevertheless, overall and leukemia-free survivals after pediatric CBT are generally comparable to those after matched unrelated donor transplantations, and it would be desirable to avoid double CBT unless the cell dose of a unit is unacceptable for transplantation.

In patients with malignant diseases, there are many factors affecting the survival rates other than engraftment (e.g., disease status at transplantation, aggressiveness of the underlying disease, comorbid conditions). Therefore, the effectiveness of engraftment promoting strategies to improve survival rates is relatively uncertain, especially considering a relatively lower rate of primary engraftment failure in recent years than that in the past. Nonetheless, there are substantial evi- dences regarding the positive impact of total body irradiation (TBI) on the outcome of CBT in both children and adults. Nakasone et al. [29] showed that the rate of neutrophil engraftment was almost 20\% higher in adult CB recipients following TBI-based myeloablative conditioning compared to that without TBI. Eapen et al. [30] compared an antithymocyte globulin (ATG)-free TBI-based regimen, named TCF (12 Gy $\mathrm{TBI}$, cyclophosphamide $120 \mathrm{mg} / \mathrm{m}^{2}$, fludarabine $75 \mathrm{mg} / \mathrm{m}^{2}$ ), with other regimens for childhood acute leukemia. The showed that TCF regimen, whether as part of a clinical trial or not, resulted in superior survival as compared to other non-trial chemotherapy- or TBI-based regimens, suggesting that a specific conditioning regimen could affect the outcome of CBT for childhood malignancy [30]. However, they failed to prove its positive impact on engraftment. In our institution, we have been using an ATG-free modified TCF regimen, containing 10 Gy TBI, for childhood acute leukemia over a decade. All patients were engrafted successfully using this regimen; notably, their event-free and overall survival reached to almost $80 \%$ (unpublished data).

The main reason for using ATG in conditioning is in vivo depletion of host T-cells in order to prevent graft rejection. However, due to its long half-life and highly variable exposure between individuals caused by variables influencing the pharmacokinetic profiles, it also affects graft T-cells to a variable degree and can have a negative impact on engraftment [31]. Although ATG has been associated with a lower incidence of GVHD, it also decreases GVL/GVM effect and delays immune reconstitution $[32,33]$. Therefore, reducing its dose or even omitting it may be a reasonable choice given that an adequate cell dose and fairly good HLA matching are ensured.

\section{CB ENGRAFTMENT AND SURVIVAL IN NON-MALIGNANT DISORDERS}

In patients with non-malignant disorders, engraftment issues have been more problematic and the outcomes of CBT in those patients have largely been dependent on successful engraftment [34-37]. Unlike patients with malignant diseases who unexceptionally receive repetitive cytotoxic and immunosuppressive chemotherapy prior to HSCT, most of those with non-malignant disorders are not exposed to such treatments before transplantation. Therefore, they are capable of exerting relatively stronger alloimmune response against the graft despite a conditioning using similar intensity. This is also true for patients with severe aplastic anemia (SAA) whose marrow cellularity has already decreased, thus requiring a 
less intensive conditioning regimen.

As mentioned earlier, the first successful CBT was performed using $C B$ from a matched related sibling donor [1]. However, a matched related CB or a fully matched unrelated $\mathrm{CB}$ unit is hardly available in clinical settings. Therefore, $\mathrm{CB}$ is mostly unrelated and partially mismatched in real practice. Nevertheless, matched related CBT has highly been successful in treating acquired and inherited bone marrow failure syndromes (BMFS) $[35,38]$. According to a study by the Eurocord and EBMT including 20 patients with acquired BMFS and 97 with inherited BMFS who were treated with matched related CBT, the cumulative incidence of neutrophil recovery by day 60 was $84 \%$ for acquired BMFS and $90 \%$ for inherited BMFS resulting in $>80 \%$ long-term survival rates [38]. In contrast, an earlier report by the Eurocord-Netcord and EBMT on the unrelated CBT in Fanconi anemia showed a disappointing outcome [34]. The neutrophil recovery rate by day 60 was only $60 \%$, and the 3 -year overall survival was $40 \%$. In this study, patients who received a nucleated cell dose greater than $4.9 \times 10^{7}$ per kg of recipients' body weight showed a superior survival rate to those with a lower cell dose, which suggested that a higher cell dose is needed for the non-malignant disorders than that required in malignant diseases $\left(2.5-3 \times 10^{7} / \mathrm{kg}\right)$. In a subsequent report in 2011, the Eurocord and EBMT compared the related and unrelated CBT for hereditary BMFS except for Fanconi anemia [35]. The engraftment rate of unrelated CB was only $55 \%$, and there was substantial difference in 3-year survival between related and unrelated CBT (95\% vs. $61 \%$ ), again proving the necessity of a higher cell dose in unrelated CBT for these non-malignant disorders. In a concurrent study by the Eurocord and EBMT reported on the unrelated CBT in SAA including mainly pediatric patients, the rates of neutrophil and platelet engraftment were only $51 \%$ and $37 \%$, respectively, resulting in very poor overall survival of $38 \%$ [36]. According to this study, infection (38\%) and poor graft performance (32\%) were the predominant causes of death followed by GVHD (7\%). In 2014, the Korean CB Registry data on the unrelated CBT for pediatric non-malignant disorders was published [37]. The neutrophil engraftment rate was $85 \%$ in patients with acquired SAA and only $37 \%$ in patients with inherited BMFS, leading to the overall survival of $54 \%$ in the former and $37 \%$ in the latter.

Because of consistent poor outcomes, CB has not been considered a good stem cell source for treating non-malignant disorders. However, a recent Japanese study showed that a certain conditioning regimen was capable of produc- ing an excellent outcome of CBT in pediatric patients with SAA [39]. They omitted ATG and used low-dose TBI (2 Gy), fludarabine (125 to $175 \mathrm{mg} / \mathrm{m}^{2}$ ), and either cyclophosphamide (50 to $100 \mathrm{mg} / \mathrm{kg}$ ) or melphalan ( 80 to $120 \mathrm{mg} / \mathrm{m}^{2}$ ) for the conditioning before transplantation. This combination led to $100 \%$ engraftment and survival in contrast to the poor engraftment and survival with other regimens. More recently, a French nationwide prospective study on the unrelated CBT in patients with idiopathic refractory SAA was published [40]. The eligibility criteria required one or two CB units, containing separately or together more than $4 \times 10^{7}$ frozen nucleated cells per kilogram of recipients' body weight. Twenty-six young patients aged between 9 and 23 years were enrolled, and they received fludarabine $\left(120 \mathrm{mg} / \mathrm{m}^{2}\right)$, cyclophosphamide (120 mg/kg), low-dose TBI (2 Gy), and lowdose ATG $(5 \mathrm{mg} / \mathrm{kg})$. There were only three graft failures, and the 1-year survival rate was $89 \%$. Recently, a Japanese retrospective study on the unrelated CBT with fludarabine (125 $\left.\mathrm{mg} / \mathrm{m}^{2}\right)$, cyclophosphamide (120 mg/kg), and low dose TBI (4 Gy) without ATG in adults with SAA was reported [41]. Although there were only six patients, all patients were engrafted and survived with a lower cell dose (median, $2.9 \times 10^{7} / \mathrm{kg}$; range, 2.2 to 4.6 ) than that used in the previous French study (median, $4.3 \times 10^{7} / \mathrm{kg}$ in single CBT; median, $3.0 \times 10^{7} / \mathrm{kg}$ in double CBT).

In 2013, we launched a new conditioning regimen for pediatric $C B$ recipients with $S A A$ in our institution by modifying the previous one; the doses of fludarabine $\left(75 \mathrm{mg} / \mathrm{m}^{2}\right)$ and cyclophosphamide $(120 \mathrm{mg} / \mathrm{kg}$ ) were reduced with the addition of 5 Gy TBI and omission of ATG in the modified conditioning regimen. All three patients achieved sustained neutrophil and platelet engraftment and survived with full donor chimerism. No patient developed severe acute or extensive chronic GVHD (unpublished data). Now, we offer upfront CBT to children and adolescents with SAA who lack a matched sibling or matched unrelated donor whenever a suitable $C B$ unit is available.

Very recently, an interesting report prospectively testing the strategy of reduced intensity single CBT with optional cord-donor leucocyte infusion (DLI) for non-malignant disorders was published [42]. Forty-four children with various diseases, mostly inherited, were enrolled, and a single CB unit containing $>3 \times 10^{7}$ frozen nucleated cells per $\mathrm{kg}$ of recipients' body weight and $>1.5 \times 10^{5} \mathrm{CD} 34+$ cells per $\mathrm{kg}$ of recipients' body weight was eligible for the transplantation. The conditioning regimen included alemtuzumab, hydroxyurea, fludarabine, melphalan, and thiotepa. Additionally, the indi- 
vidualized doses of alemtuzumab and hydroxyurea was chosen depending on the patient's condition. Five percent of thawed CB cells was re-cryopreserved for possible DLI, which was actually performed in 20 patients with conditions such as life-threatening viral infection, mixed T-cell chimerism, and sluggish T-cell reconstitution. Surprisingly, all evaluable patients achieved both neutrophil and platelet engraftment, and the 5-year survival rate (85\%) was excellent without an increase of GVHD.

In summary, despite the consistent poor outcome of unrelated CBT in inherited non-malignant disorders in the past, both engraftment and survival rates are likely to be further improved by optimizing the conditioning regimen with or without an appropriate post-transplant intervention as needed. In addition, although limited, recent reports demonstrate a remarkable improvement in the unrelated CBT in patients with acquired SAA using ATG-free conditioning regimens containing low-dose TBI, fludarabine, and cyclophosphamide or using a similar low-dose ATG-containing regimen.

\section{EX VIVO EXPANSION OF CB STEM CELLS}

Ex vivo expansion of $\mathrm{CB}$ stem cells is one of the most attractive strategies to enhance graft performance. A number of methods for ex vivo expansion, such as Notch-mediated expansion [43-45], MSC coculture [46,47], nicotinamide [48-50], StemRegenin-1 [51,52], copper chelation [53,54], chrysin [55], and UM171 [56,57], have been explored and some of them have already been tested in clinical trials (Table 1). Ideally, expanded stem cells should maintain their quality by in- hibiting hematopoietic differentiation, have to be safe and feasible for clinical application, must result in enhanced engraftment, and ultimately should lead to an improved survival of the recipients.

Notch family members are widespread by hematopoietic cells, and Notch signaling in combination with cytokines induces a robust increase in marrow repopulating ability of $\mathrm{CB}$ cells [43]. The first clinical trial with CB cells that have undergone Notch-mediated expansion was conducted in recipients of double CBT, and one of the two units was infused after ex vivo expansion [44]. The mean fold increase of nucleated cells was $>500$ times and that of CD34+ cells was $>160$ times, leading to a faster neutrophil engraftment compared to that in the historical controls (median reduction in time to neutrophil recovery, 10 days). This is the first report that demonstrated the rapid myeloid engraftment achieved using ex vivo expanded cells in human. The safety of Notch ligand-expanded progenitor cells was also demonstrated by a subsequent phase I study for patients with acute myeloid leukemia following intensive chemotherapy [45].

The first clinical trial using ex vivo expanded $\mathrm{CB}$ cells by MSC coculture was reported in 2012 [47]. Twenty-four recipients of double $\mathrm{CBT}$ received one unit $\mathrm{CB}$ cells expanded ex vivo in cocultures with stromal precursor antigen (STRO)-3+ MSCs along with one unmanipulated unit. The median fold increases in nucleated cells and CD34+ cells were 12.2 and 30.1 times, respectively. This study also demonstrated improved engraftment kinetics in study subjects as compared to that in the historical controls, resulting in a median reduction in time to neutrophil recovery of 9 days $(P<0.001)$ and a

Table 1. Overview of representative clinical studies on cord blood cells expanded ex vivo using small molecules or mesenchymal stem/ stromal cell coculture

\begin{tabular}{|c|c|c|c|c|c|c|c|c|c|c|}
\hline \multirow[t]{2}{*}{ Study } & \multirow{2}{*}{$\begin{array}{l}\text { Study } \\
\text { phase }\end{array}$} & \multirow{2}{*}{$\begin{array}{l}\text { Expansion } \\
\text { strategy }\end{array}$} & \multirow{2}{*}{$\begin{array}{l}\text { CB } \\
\text { units } \\
(n)\end{array}$} & \multicolumn{2}{|c|}{$\begin{array}{l}\text { Subjects } \\
\text { (n) }\end{array}$} & \multirow{2}{*}{$\begin{array}{l}\text { Median fold } \\
\text { increase of } \\
\text { CD34+ cells } \\
\text { (range) }\end{array}$} & \multicolumn{2}{|c|}{$\begin{array}{l}\text { Engraftment rate } \\
\qquad(\%)\end{array}$} & \multicolumn{2}{|c|}{$\begin{array}{l}\text { Median reduction in } \\
\text { time to engraftment } \\
\text { (day) }\end{array}$} \\
\hline & & & & Patients & $\begin{array}{c}\text { Historical } \\
\text { controls }\end{array}$ & & Neutrophil & Platelet & Neutrophil & Platelet \\
\hline Delaney et al. [44] & I & Notch ligand & $2^{a)}$ & 10 & 26 & $164^{d)}(41-471)$ & 90 & NR & 10 & NR \\
\hline de Lima et al. [47] & $\mathrm{I} / \mathrm{II}$ & MSC coculture & $2^{a)}$ & 24 & 80 & $30.1(0-137.8)$ & 96 & 75 & 9 & 7 \\
\hline Horwitz et al. [50] & $\mathrm{I} / \mathrm{II}$ & Nicotinamide & $1^{\text {b) }}$ & 36 & 146 & 33 (NR) & 94 & 81 & 9.5 & 12 \\
\hline Wagner et al. [52] & $1 / 11$ & StemRegenin-1 & $2^{a)}$ & 17 & 111 & $330(67-848)$ & 100 & 76 & 9 & 40 \\
\hline Stiff et al. [54] & $\|/ I\|$ & TEPA & $1^{c)}$ & 101 & 295 & $90(6-398)$ & 91.9 & 65.6 & 7 & 51 \\
\hline Cohen et al. [57] & $\mathrm{I} / \mathrm{II}$ & UM171 & $1^{\mathrm{b})}$ & 22 & - & $35(26-49)$ & 100 & 100 & - & - \\
\hline
\end{tabular}

CB, cord blood; MSC, mesenchymal stem/stromal cell; NR, not reported; TEPA, tetraethylenepentamine.

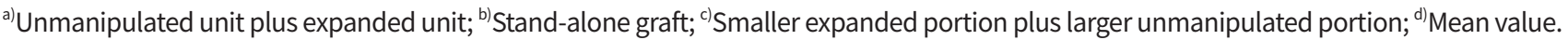


median reduction in time to platelet recovery of 7 days $(P=0.03)$.

Nicotinamide is a small molecule which is known to inhibit the differentiation of hematopoietic stem and progenitor cells expanded by cytokine-induced ex vivo cultures and to enhance their functionality $[48,49]$. Recently, a phase I/II study assessing the safety and efficacy of $\mathrm{CB}$ grafts that were expanded ex vivo in the presence of nicotinamide and transplanted after myeloablative conditioning as a stand-alone graft was reported [50]. The expanded grafts showed 33-fold increase in CD34+ cells leading to a faster engraftment in the recipients of ex vivo expanded $\mathrm{CB}$ cells than that in the historical controls. The cumulative incidence of neutrophil engraftment was $94 \%$, and the expanded grafts shortened the time to neutrophil (median, 9.5 days; $P<0.001$ ) and platelet (median, 12 days; $P<0.001$ ) recovery.

StemRegenin-1, an aryl hydrocarbon receptor antagonist, is a small molecule first identified in 2010 [51]. This promoted the expansion of CD34+ hematopoietic progenitor cells retaining their multi-lineage potential and significantly augmented the early and late engraftment of human cells in immunodeficient mice. A phase I/II study was performed in recipients of double CBT, they received one unmanipulated and one expanded unit of CB. CD34+ cells were expanded up to 848 times (median, 330; range, 67 to 848 ), leading to a substantially faster engraftment in the study subjects than that in the historical controls [52]. The marked expansion, absence of graft failure, and enhanced hematopoietic recovery supported testing of the StemRegenin-1-expanded single CB unit as a stand-alone graft.

Copper chelation by tetraethylenepentamine in combination with various cytokines inhibits stem cell differentiation transiently during the expansion period [53]. A cohort-controlled study using these expanded cells was recently reported [54]. Only a small portion of a CB unit was used for expansion in this trial, and the larger fraction containing nucleated cells at least greater than $1 \times 10^{7} / \mathrm{kg}$ served as the unmanipulated fraction. The study presented an encouraging outcome showing a better engraftment kinetics and a significantly better 100-day survival in recipients as compared to that in the historical controls.

UM171, an HSC self-renewal agonist, has been shown to expand CB stem cells and enhance multi-lineage blood cell reconstitution in mice [56]. Very recently, a single-arm, phase I/II study of single UM171-expanded CBT was reported in patients with hematologic malignancies [57]. In this trial, no graft failure occurred in 22 patients who received single
UM171-expanded CBT. The median time to neutrophil and platelet recovery was 18 and 42 days, respectively, without any unexpected adverse event.

As noted by a number of clinical trials, ex vivo CB expansion strategies are obviously encouraging in terms of facilitating engraftment following CBT. However, their impact on survival outcomes is uncertain due to the lack of large-scale long-term follow-up study on these measures. Further optimization of these strategies is expected to produce better outcomes of CBT in the near future.

\section{COTRANSPLANTATION OF MSCS WITH CB}

Cotransplantation of MSCs is another attractive investigational approach aiming at enhancing HSC engraftment. MSCs are known to play an important role in supporting hematopoiesis, and they also have immunomodulatory properties which enables them to suppress host allogeneic responses against the donor graft [58-60]. An early study showed that cotransplanted bone marrow-derived MSCs were able to promote the engraftment of $\mathrm{CB} C D 34+$ cells in sublethally irradiated non-obese diabetic/severe combined immunodeficiency (NOD/SCID) mice, and the effect was more prominent when the CB stem cell number was limited [61]. Previously, we demonstrated that the immunosuppressive abilities of MSCs are comparable with those derived from different sources including bone marrow, adipose tissue, $C B$, and Wharton-jelly [62]. More recently, we also showed that the engraftment promoting effect of MSCs is consistently observed regardless of the MSC source including bone marrow, adipose tissue, and CB [63]. Furthermore, we conducted a clinical trial using the third party CB-derived MSCs in pediatric $\mathrm{CB}$ recipients. All the patients cotransplanted with MSCS achieved both neutrophil and platelet engraftment faster than the historical controls [64]. However, in the past clinical trials on the cotransplantation of MSCs with $\mathrm{CB}$, the engraftment promoting effect was not consistently observed. In a study by MacMillan et al. [65], all eight pediatric CB recipients cotransplanted with MSCs were successfully engrafted at a median of 19 days. However, a subsequent study by Gonzalo-Daganzo et al. [66] failed to demonstrate engraftment promoting effect of MSCs in adult recipients. This inconsistency might partly originate from the heterogeneity and/or limited functionality of MSCs in their naïve forms.

Next, it is interesting to see if certain techniques like preconditioning and genetic modifications could generate more potent and functionally augmented MSCs and if the func- 


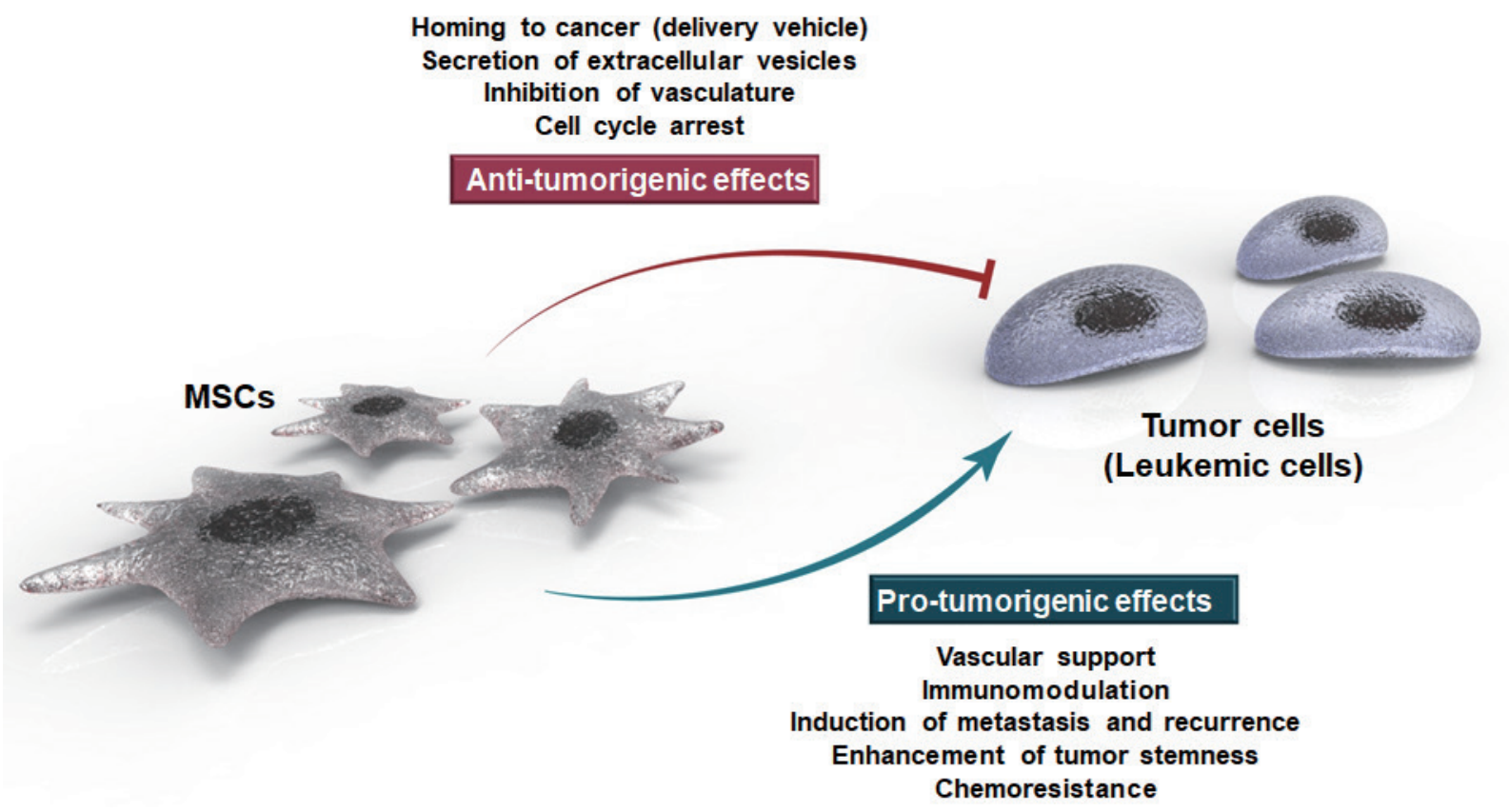

Fig. 1. Mesenchymal stem/stromal cells (MSCs) exhibit a dual role in hematologic malignancy. They tend to not only inhibit tumor growth by suppressing tumor cell proliferation but also promote tumor growth by suppressing tumor cell apoptosis [80]. Adapted from Lee et al. [80], licensed under a Creative Commons Attribution 4.0 International (CC BY 4.0) License (https://creativecommons.org/licenses/by/4.0/).

tionally modified MSCs would be safe and more effective as well. Recently, we showed that MSCs preconditioned with interferon- $\gamma$ significantly reduced the symptoms of GVHD in NOD/SCID mice, thereby increasing their survival rate when compared with naïve MSC-infused mice [67]. Upon interferon- $\gamma$-stimulation, a robust increase in indoleamine 2,3-dioxygenase (IDO) gene expression was observed. However, infusion of interferon- $\gamma$-primed MSCs in which IDO was downregulated did not elicit this effect, suggesting a pivotal role of IDO in the immunosuppressive function of MSCs. Importantly, these preconditioned MSCs and IDO-overexpressing MSCS showed similar survival of GVHD mice. In addition to interferon- $\gamma$-priming, culture density itself affects the gene expression profiles of MSCs. MSCs cultured at high density exhibited increased expression of various cytokine, chemokine, and growth factor genes involved in immunosuppression, migration, homing, angiogenesis, and reconstitution of damaged tissues [68]. These findings suggest that functional augmentation by means of certain measures can potentiate the innate abilities of MSCs including immunosuppressive and engraftment enhancing properties. Unlike other strategies aiming at enhancing graft performance, MSCs have also been useful in controlling steroid-refractory severe GVHD as shown in numerous previous studies [69-79]. Among them, a study by Auletta et al. [77] revealed the GVHD attenuating effect of
MSCs without the loss of their GVL/GVM activity. However, MSCs have both anti-tumorigenic and pro-tumorigenic properties although they are not well established in hematologic malignancies (Fig. 1) [80]. Therefore, special precautions need to be taken while developing MSC-based cell therapies. Improving the quality of life as well as survival of recipients is the ultimate goal of HSCT. Thus, strategies aiming at controlling severe GVHD and preventing regimen-related toxicities and relapse are also as important as those aiming at facilitating engraftment in order to achieve the goal. Considering the safety and potential benefits of MSCs, the establishment of optimal treatment strategies with MSCs might pave the way for substantial improvement in the outcomes of not only CBT but also other types of allogeneic HSCT.

\section{CONCLUSION}

Although a minority of pediatric CB recipients with hematologic malignancy suffer from primary graft failure, their survival appears to be comparable to that of haploidentical or matched unrelated donor recipients and even to that of matched related donor recipients in recent years. However, a delay in both myeloid and platelet engraftment is not likely to be overcome by double $\mathrm{CB}$, which requires effective strategies to enhance engraftment. Engraftment failure has been 
especially problematic in $\mathrm{CB}$ recipients with non-malignant disorders. Nevertheless, recent data suggest that it can be overcome by modifying conditioning regimens with or without a specific post-transplant intervention. Thus, the optimization of conditioning regimens depending on the patients' underlying disease might be the most practical and readily applicable approach along with selecting the best available $\mathrm{CB}$ unit to improve the outcome of CBT without an additional financial burden. There have been remarkable advances in ex vivo CB stem cell expansion technologies, and future clinical trials with a larger cohort will measure the effectiveness of these strategies. Despite some limitations of naïve MSCs in promoting $\mathrm{CB}$ graft performance, their innate immunosuppressive property is attractive enough to draw clinicians' attention who are caring for patients under complicated post-transplant situations including severe GVHD. In this circumstance, further studies are needed to verify if functionally augmented MSCS would be able to help overcome the weaknesses of CBT.

\section{CONFLICTS OF INTEREST}

No potential conflict of interest relevant to this article was reported.

\section{ACKNOWLEDGMENTS}

This work was supported by the National Research Foundation of Korea (NRF) grant funded by the Korea government (MSIT) (grant number: 2019R1A2C1084486) and by a grant of the Korea Health Technology R\&D Project through the Korea Health Industry Development Institute (KHIDI) funded by the Ministry of Health \& Welfare, Republic of Korea (grant number: HI14C3484).

\section{ORCID}

Keon Hee Yoo https://orcid.org/0000-0002-5980-7912

\section{AUTHOR CONTRIBUTIONS}

Conception or design: KHY.

Acquisition, analysis, or interpretation of data: KHY.

Drafting the work or revising: KHY.

Final approval of the manuscript: KHY.

\section{REFERENCES}

1. Gluckman E, Broxmeyer HA, Auerbach AD, Friedman HS, Douglas GW, Devergie A, et al. Hematopoietic reconstitution in a patient with Fanconi's anemia by means of umbilical-cord blood from an HLA-identical sibling. N Engl J Med 1989;321:1174-8.

2. Laporte JP, Gorin NC, Rubinstein P, Lesage S, Portnoi MF, Barbu V, et al. Cord-blood transplantation from an unrelated donor in an adult with chronic myelogenous leukemia. N Engl J Med 1996;335:167-70.

3. Ballen K. Update on umbilical cord blood transplantation. F1000Res 2017;6:1556.

4. Konuma T, Tsukada N, Kanda J, Uchida N, Ohno Y, Miyakoshi S, et al. Comparison of transplant outcomes from matched sibling bone marrow or peripheral blood stem cell and unrelated cord blood in patients 50 years or older. Am J Hematol 2016;91:E284-92.

5. Baron F, Labopin M, Ruggeri A, Ehninger G, Bonifazi F, Stelljes $\mathrm{M}$, et al. Umbilical cord blood versus unrelated donor transplantation in adults with primary refractory or relapsed acute myeloid leukemia: a report from Eurocord, the Acute Leukemia Working Party and the Cord Blood Committee of the Cellular Therapy and Immunobiology Working Party of the EBMT. Blood Cancer J 2019; 9:46.

6. Fuchs EJ, O'Donnell PV, Eapen M, Logan BR, Antin JH, Dawson $\mathrm{P}$, et al. Double unrelated umbilical cord blood versus HLA-haploidentical bone marrow transplantation (BMT CTN 1101). Blood 2021;137:420-8.

7. Lou X, Zhao C, Chen H. Unrelated donor umbilical cord blood transplant versus unrelated hematopoietic stem cell transplant in patients with acute leukemia: a meta-analysis and systematic review. Blood Rev 2018;32: 192-202.

8. Robin M, Ruggeri A, Labopin M, Niederwieser D, Tabrizi R, Sanz G, et al. Comparison of unrelated cord blood and peripheral blood stem cell transplantation in adults with myelodysplastic syndrome after reduced-intensity conditioning regimen: a collaborative study from Eurocord (Cord blood Committee of Cellular Therapy \& Immunobiology Working Party of EBMT) and Chronic Malignancies Working Party. Biol Blood Marrow Transplant 2015;21: 489-95.

9. Stanevsky A, Goldstein G, Nagler A. Umbilical cord blood transplantation: pros, cons and beyond. Blood Rev 2009; 23:199-204. 
10. Rocha V. Umbilical cord blood cells from unrelated donor as an alternative source of hematopoietic stem cells for transplantation in children and adults. Semin Hematol 2016;53:237-45.

11. Shi-Xia X, Xian-Hua T, Xiang-Feng T. Unrelated umbilical cord blood transplantation and unrelated bone marrow transplantation in children with hematological disease: a meta-analysis. Pediatr Transplant 2009;13:278-84.

12. Yoo KH, Lee SH, Sung KW, Koo HH, Chung NG, Cho B, et al. Current status of pediatric umbilical cord blood transplantation in Korea: a multicenter retrospective analysis of 236 cases. Am J Hematol 2011;86:12-7.

13. Fuji S, Oshima K, Ohashi K, Sawa M, Saito T, Eto T, et al. Impact of pretransplant donor-specific anti-HLA antibodies on cord blood transplantation on behalf of the Transplant Complications Working Group of Japan Society for Hematopoietic Cell Transplantation. Bone Marrow Transplant 2020;55:722-8.

14. Morin-Zorman S, Loiseau P, Taupin JL, Caillat-Zucman S. Donor-specific anti-HLA antibodies in allogeneic hematopoietic stem cell transplantation. Front Immunol 2016; 7:307.

15. Ruggeri A, Rocha V, Masson E, Labopin M, Cunha R, Absi L, et al. Impact of donor-specific anti-HLA antibodies on graft failure and survival after reduced intensity conditioning-unrelated cord blood transplantation: a Eurocord, Société Francophone d'Histocompatibilité et d'Immunogénétique (SFHI) and Société Française de Greffe de Moelle et de Thérapie Cellulaire (SFGM-TC) analysis. Haematologica 2013;98:1154-60.

16. Passweg JR, Baldomero H, Basak GW, Chabannon C, Corbacioglu S, Duarte R, et al. The EBMT activity survey report 2017: a focus on allogeneic HCT for nonmalignant indications and on the use of non-HCT cell therapies. Bone Marrow Transplant 2019;54:1575-85.

17. Patil S, Potter V, Mohty M. Review of conditioning regimens for haplo-identical donor transplants using post-transplant cyclophosphamide in recipients of G-CSF mobilised peripheral stem cell. Cancer Treat Rev 2020;89:102071.

18. Im A, Rashidi A, Wang T, Hemmer M, MacMillan ML, Pidala $J$, et al. Risk factors for graft-versus-host disease in haploidentical hematopoietic cell transplantation using post-transplant cyclophosphamide. Biol Blood Marrow Transplant 2020;26:1459-68.

19. Bacigalupo A, Raiola AM, Dominietto A, Di Grazia C, Gualandi F, Lint MTV, et al. Graft versus host disease in unmanipulated haploidentical marrow transplantation with a modified post-transplant cyclophosphamide (PT-CY) regimen: an update on 425 patients. Bone Marrow Transplant 2019;54:708-12.

20. Giannotti F, Labopin M, Shouval R, Sanz J, Arcese W, Angelucci $\mathrm{E}$, et al. Haploidentical transplantation is associated with better overall survival when compared to single cord blood transplantation: an EBMT-Eurocord study of acute leukemia patients conditioned with thiotepa, busulfan, and fludarabine. J Hematol Oncol 2018;11:110.

21. Sanz J, Montoro J, Solano C, Valcarcel D, Sampol A, Ferra $\mathrm{C}$, et al. Prospective randomized study comparing myeloablative unrelated umbilical cord blood transplantation versus HLA-haploidentical related stem cell transplantation for adults with hematologic malignancies. Biol Blood Marrow Transplant 2020;26:358-66.

22. Mo XD, Tang BL, Zhang XH, Zheng CC, Xu LP, Zhu XY, et al. Comparison of outcomes after umbilical cord blood and unmanipulated haploidentical hematopoietic stem cell transplantation in children with high-risk acute lymphoblastic leukemia. Int J Cancer 2016;139:2106-15.

23. Li D, Li X, Liao L, Li N. Unrelated cord blood transplantation versus haploidentical transplantation in adult and pediatric patients with hematological malignancies: a meta-analysis and systematic review. Am J Blood Res 2020;10:1-10.

24. Gutman JA, Leisenring W, Appelbaum FR, Woolfrey AE, Delaney C. Low relapse without excessive transplant-related mortality following myeloablative cord blood transplantation for acute leukemia in complete remission: a matched cohort analysis. Biol Blood Marrow Transplant 2009;15:1122-9.

25. Zheng CC, Zhu XY, Tang BL, Zhang XH, Zhang L, Geng LQ, et al. Clinical separation of CGvHD and GvL and better GvHD-free/relapse-free survival (GRFS) after unrelated cord blood transplantation for AML. Bone Marrow Transplant 2017;52:88-94.

26. Sakaguchi H, Watanabe N, Matsumoto K, Yabe H, Kato S, Ogawa A, et al. Comparison of donor sources in hematopoietic stem cell transplantation for childhood acute leukemia: a nationwide retrospective study. Biol Blood Marrow Transplant 2016;22:2226-34.

27. Keating AK, Langenhorst J, Wagner JE, Page KM, Veys P, Wynn RF, et al. The influence of stem cell source on transplant outcomes for pediatric patients with acute myeloid leukemia. Blood Adv 2019;3:1118-28.

28. Wagner JE Jr, Eapen M, Carter S, Wang Y, Schultz KR, Wall DA, et al. One-unit versus two-unit cord-blood transplan- 
tation for hematologic cancers. N Engl J Med 2014;371: 1685-94.

29. Nakasone H, Fuji S, Yakushijin K, Onizuka M, Shinohara A, Ohashi K, et al. Impact of total body irradiation on successful neutrophil engraftment in unrelated bone marrow or cord blood transplantation. Am J Hematol 2017; 92:171-8.

30. Eapen M, Kurtzberg J, Zhang MJ, Hattersely G, Fei M, Mendizabal A, et al. Umbilical cord blood transplantation in children with acute leukemia: impact of conditioning on transplantation outcomes. Biol Blood Marrow Transplant 2017;23:1714-21.

31. de Koning C, Admiraal R, Nierkens S, Boelens JJ. Immune reconstitution and outcomes after conditioning with anti-thymocyte-globulin in unrelated cord blood transplantation; the good, the bad, and the ugly. Stem Cell Investig 2017;4:38.

32. Gooptu M, Kim HT, Chen YB, Rybka W, Artz A, Boyer M, et al. Effect of antihuman T lymphocyte globulin on immune recovery after myeloablative allogeneic stem cell transplantation with matched unrelated donors: analysis of immune reconstitution in a double-blind randomized controlled trial. Biol Blood Marrow Transplant 2018;24: 2216-23.

33. Castillo N, Garcia-Cadenas I, Barba P, Canals C, Diaz-Heredia $\mathrm{C}$, Martino $\mathrm{R}$, et al. Early and long-term impaired $\mathrm{t}$ lymphocyte immune reconstitution after cord blood transplantation with antithymocyte globulin. Biol Blood Marrow Transplant 2017;23:491-7.

34. Gluckman E, Rocha V, lonescu I, Bierings M, Harris RE, Wagner J, et al. Results of unrelated cord blood transplant in fanconi anemia patients: risk factor analysis for engraftment and survival. Biol Blood Marrow Transplant 2007;13:1073-82.

35. Bizzetto R, Bonfim C, Rocha V, Socie G, Locatelli F, Chan K, et al. Outcomes after related and unrelated umbilical cord blood transplantation for hereditary bone marrow failure syndromes other than Fanconi anemia. Haematologica 2011;96:134-41.

36. de Latour RP, Purtill D, Ruggeri A, Sanz G, Michel G, Gandemer $\mathrm{V}$, et al. Influence of nucleated cell dose on overall survival of unrelated cord blood transplantation for patients with severe acquired aplastic anemia: a study by eurocord and the aplastic anemia working party of the European Group for Blood and Marrow Transplantation. Biol Blood Marrow Transplant 2011;17:78-85.

37. Park M, Lee YH, Kang HR, Lee JW, Kang HJ, Park KD, et al.
Unrelated donor cord blood transplantation for non-malignant disorders in children and adolescents. Pediatr Transplant 2014;18:221-9.

38. Pagliuca S, de Latour RP, Volt F, Locatelli F, Zecca M, Dalle $\mathrm{JH}$, et al. Long-term outcomes of cord blood transplantation from an HLA-identical sibling for patients with bone marrow failure syndromes: a report from Eurocord, Cord Blood Committee and Severe Aplastic Anemia Working Party of the European Society for Blood and Marrow Transplantation. Biol Blood Marrow Transplant 2017;23:1939-48.

39. Kudo K, Muramatsu H, Narita A, Yoshida N, Kobayashi R, Yabe $\mathrm{H}$, et al. Unrelated cord blood transplantation in aplastic anemia: is anti-thymocyte globulin indispensable for conditioning? Bone Marrow Transplant 2017;52: 1659-61.

40. de Latour RP, Chevret S, Jubert C, Sirvent A, Galambrun C, Ruggeri A, et al. Unrelated cord blood transplantation in patients with idiopathic refractory severe aplastic anemia: a nationwide phase 2 study. Blood 2018;132:750-4.

41. Ochi T, Onishi Y, Nasu K, Onodera K, Kobayashi M, Ichikawa $\mathrm{S}$, et al. Umbilical cord blood transplantation using reduced-intensity conditioning without antithymocyte globulin in adult patients with severe aplastic anemia. Biol Blood Marrow Transplant 2019;25:e55-9.

42. Vander Lugt MT, Chen X, Escolar ML, Carella BA, Barnum JL, Windreich RM, et al. Reduced-intensity single-unit unrelated cord blood transplant with optional immune boost for nonmalignant disorders. Blood Adv 2020;4:3041-52.

43. Delaney C, Varnum-Finney B, Aoyama K, Brashem-Stein C, Bernstein ID. Dose-dependent effects of the Notch ligand Delta1 on ex vivo differentiation and in vivo marrow repopulating ability of cord blood cells. Blood 2005;106: 2693-9.

44. Delaney C, Heimfeld S, Brashem-Stein C, Voorhies H, Manger RL, Bernstein ID. Notch-mediated expansion of human cord blood progenitor cells capable of rapid myeloid reconstitution. Nat Med 2010;16:232-6.

45. Delaney C, Milano F, Cicconi L, Othus M, Becker PS, Sandhu $\mathrm{V}$, et al. Infusion of a non-HLA-matched ex-vivo expanded cord blood progenitor cell product after intensive acute myeloid leukaemia chemotherapy: a phase 1 trial. Lancet Haematol 2016;3:e330-9.

46. McNiece I, Harrington J, Turney J, Kellner J, Shpall EJ. Ex vivo expansion of cord blood mononuclear cells on mesenchymal stem cells. Cytotherapy 2004;6:311-7.

47. de Lima M, McNiece I, Robinson SN, Munsell M, Eapen M, Horowitz $M$, et al. Cord-blood engraftment with ex vivo 
mesenchymal-cell coculture. N Engl J Med 2012;367:230515.

48. Peled T, Shoham H, Aschengrau D, Yackoubov D, Frei G, Rosenheimer GN, et al. Nicotinamide, a SIRT1 inhibitor, inhibits differentiation and facilitates expansion of hematopoietic progenitor cells with enhanced bone marrow homing and engraftment. Exp Hematol 2012;40:342-55.

49. Horwitz ME, Chao NJ, Rizzieri DA, Long GD, Sullivan KM, Gasparetto C, et al. Umbilical cord blood expansion with nicotinamide provides long-term multilineage engraftment. J Clin Invest 2014;124:3121-8.

50. Horwitz ME, Wease S, Blackwell B, Valcarcel D, Frassoni F, Boelens JJ, et al. Phase I/II study of stem-cell transplantation using a single cord blood unit expanded ex vivo with nicotinamide. J Clin Oncol 2019;37:367-74.

51. Boitano AE, Wang J, Romeo R, Bouchez LC, Parker AE, Sutton SE, et al. Aryl hydrocarbon receptor antagonists promote the expansion of human hematopoietic stem cells. Science 2010;329:1345-8.

52. Wagner JE Jr, Brunstein CG, Boitano AE, DeFor TE, McKenna $D$, Sumstad $D$, et al. Phase I/II trial of StemRegenin-1 expanded umbilical cord blood hematopoietic stem cells supports testing as a stand-alone graft. Cell Stem Cell 2016;18:144-55.

53. Peled T, Landau E, Mandel J, Glukhman E, Goudsmid NR, Nagler A, et al. Linear polyamine copper chelator tetraethylenepentamine augments long-term ex vivo expansion of cord blood-derived CD34+ cells and increases their engraftment potential in NOD/SCID mice. Exp Hematol 2004;32:547-55.

54. Stiff PJ, Montesinos P, Peled T, Landau E, Goudsmid NR, Mandel J, et al. Cohort-controlled comparison of umbilical cord blood transplantation using carlecortemcel-L, a single progenitor-enriched cord blood, to double cord blood unit transplantation. Biol Blood Marrow Transplant 2018; 24:1463-70.

55. Li Y, He M, Zhang W, Yang M, Ding Y, Xu S, et al. Antioxidant small molecule compound chrysin promotes the self-renewal of hematopoietic stem cells. Front Pharmacol 2020;11:399.

56. Fares I, Chagraoui J, Lehnertz B, MacRae T, Mayotte N, Tomellini E, et al. EPCR expression marks UM171-expanded CD34+ cord blood stem cells. Blood 2017;129:3344-51.

57. Cohen S, Roy J, Lachance S, Delisle JS, Marinier A, Busque L, et al. Hematopoietic stem cell transplantation using single UM171-expanded cord blood: a single-arm, phase 1-2 safety and feasibility study. Lancet Haematol 2020;7:e134-45.

58. Le Blanc K. Immunomodulatory effects of fetal and adult mesenchymal stem cells. Cytotherapy 2003;5:485-9.

59. Dazzi F, Ramasamy R, Glennie S, Jones SP, Roberts I. The role of mesenchymal stem cells in haemopoiesis. Blood Rev 2006;20:161-71.

60. Uccelli A, Moretta L, Pistoia V. Immunoregulatory function of mesenchymal stem cells. Eur J Immunol 2006;36:256673.

61. Noort WA, Kruisselbrink AB, in't Anker PS, Kruger M, van Bezooijen RL, de Paus RA, et al. Mesenchymal stem cells promote engraftment of human umbilical cord blood-derived CD34(+) cells in NOD/SCID mice. Exp Hematol 2002; 30:870-8.

62. Yoo KH, Jang IK, Lee MW, Kim HE, Yang MS, Eom Y, et al. Comparison of immunomodulatory properties of mesenchymal stem cells derived from adult human tissues. Cell Immunol 2009;259:150-6.

63. Lee SH, Kim DS, Lee MW, Noh YH, Jang IK, Kim DH, et al. A strategy for enhancing the engraftment of human hematopoietic stem cells in NOD/SCID mice. Ann Hematol 2013; 92:1595-602.

64. Lee SH, Lee MW, Yoo KH, Kim DS, Son MH, Sung KW, et al. Co-transplantation of third-party umbilical cord blood-derived MSCs promotes engraftment in children undergoing unrelated umbilical cord blood transplantation. Bone Marrow Transplant 2013;48:1040-5.

65. Macmillan ML, Blazar BR, DeFor TE, Wagner JE. Transplantation of ex-vivo culture-expanded parental haploidentical mesenchymal stem cells to promote engraftment in pediatric recipients of unrelated donor umbilical cord blood: results of a phase I-II clinical trial. Bone Marrow Transplant 2009;43:447-54.

66. Gonzalo-Daganzo R, Regidor C, Martin-Donaire T, Rico MA, Bautista G, Krsnik I, et al. Results of a pilot study on the use of third-party donor mesenchymal stromal cells in cord blood transplantation in adults. Cytotherapy 2009; 11:278-88.

67. Kim DS, Jang IK, Lee MW, Ko YJ, Lee DH, Lee JW, et al. Enhanced immunosuppressive properties of human mesenchymal stem cells primed by interferon- $\gamma$. EBioMedicine 2018;28:261-73.

68. Kim DS, Lee MW, Yoo KH, Lee TH, Kim HJ, Jang IK, et al. Gene expression profiles of human adipose tissue-derived mesenchymal stem cells are modified by cell culture density. PLoS One 2014;9:e83363.

69. Le Blanc K, Rasmusson I, Sundberg B, Gotherstrom C, Has- 
san M, Uzunel M, et al. Treatment of severe acute graft-versus-host disease with third party haploidentical mesenchymal stem cells. Lancet 2004;363:1439-41.

70. Yanez R, Lamana ML, Garcia-Castro J, Colmenero I, Ramirez M, Bueren JA. Adipose tissue-derived mesenchymal stem cells have in vivo immunosuppressive properties applicable for the control of the graft-versus-host disease. Stem Cells 2006;24:2582-91.

71. Le Blanc K, Frassoni F, Ball L, Locatelli F, Roelofs H, Lewis I, et al. Mesenchymal stem cells for treatment of steroid-resistant, severe, acute graft-versus-host disease: a phase II study. Lancet 2008;371:1579-86.

72. Baron F, Lechanteur C, Willems E, Bruck F, Baudoux E, Seidel $L$, et al. Cotransplantation of mesenchymal stem cells might prevent death from graft-versus-host disease (GVHD) without abrogating graft-versus-tumor effects after HLA-mismatched allogeneic transplantation following nonmyeloablative conditioning. Biol Blood Marrow Transplant 2010;16:838-47.

73. Wu KH, Chan CK, Tsai C, Chang YH, Sieber M, Chiu TH, et al. Effective treatment of severe steroid-resistant acute graftversus-host disease with umbilical cord-derived mesenchymal stem cells. Transplantation 2011;91:1412-6.

74. Kuzmina LA, Petinati NA, Parovichnikova EN, Lubimova LS, Gribanova EO, Gaponova TV, et al. Multipotent mesenchymal stromal cells for the prophylaxis of acute graftversus-host disease-a phase II study. Stem Cells Int 2012; 2012:968213.

75. Kurtzberg J, Prockop S, Teira P, Bittencourt H, Lewis V, Chan KW, et al. Allogeneic human mesenchymal stem cell therapy (remestemcel-L, Prochymal) as a rescue agent for severe refractory acute graft-versus-host disease in pediatric patients. Biol Blood Marrow Transplant 2014; 20:229-35.

76. Peng Y, Chen X, Liu Q, Zhang X, Huang K, Liu L, et al. Mesenchymal stromal cells infusions improve refractory chronic graft versus host disease through an increase of CD5+ regulatory $B$ cells producing interleukin 10 . Leukemia 2015;29:636-46.

77. Auletta JJ, Eid SK, Wuttisarnwattana P, Silva I, Metheny L, Keller MD, et al. Human mesenchymal stromal cells attenuate graft-versus-host disease and maintain graft-versus-leukemia activity following experimental allogeneic bone marrow transplantation. Stem Cells 2015;33:60114.

78. Bader P, Kuci Z, Bakhtiar S, Basu O, Bug G, Dennis M, et al. Effective treatment of steroid and therapy-refractory acute graft-versus-host disease with a novel mesenchymal stromal cell product (MSC-FFM). Bone Marrow Transplant 2018;53:852-62.

79. Kurtzberg J, Abdel-Azim H, Carpenter P, Chaudhury S, Horn B, Mahadeo K, et al. A phase 3, single-arm, prospective study of remestemcel-L, ex vivo culture-expanded adult human mesenchymal stromal cells for the treatment of pediatric patients who failed to respond to steroid treatment for acute graft-versus-host disease. Biol Blood Marrow Transplant 2020;26:845-54.

80. Lee MW, Ryu S, Kim DS, Lee JW, Sung KW, Koo HH, et al. Mesenchymal stem cells in suppression or progression of hematologic malignancy: current status and challenges. Leukemia 2019;33:597-611. 